TEACHING CASE REPORT

\section{Emergency battlefield cricothyrotomy}

The case: A 19-year-old Afghan man was critically injured after a blast from an improvised explosive device. A Canadian Forces medic treated him within minutes of the injury. On initial assessment in the field, the man was conscious and breathing despite extensive facial injuries involving the mouth, oral cavity and mandible. He had also lost parts of his left forearm and lower left leg in the explosion, which had caused extensive soft tissue, neurovascular and bone injury. Because of arterial hemorrhage from his extremities, the medic placed tourniquets on both injured limbs (Figure 1).

The patient was transported by land ambulance to a medical aid station located 30 minutes away. The facility consisted of a simple resuscitation bay where medics had access to supplemental oxygen, better lighting, a warmer environment and more monitoring equipment; however, no physician was present. On arrival, the patient was tachypneic with a respiratory rate of 35 breaths $/ \mathrm{min}$, his oxygen saturation was $80 \%$, and he was beginning to inhale blood. His blood pressure was $100 / 60 \mathrm{~mm} \mathrm{Hg}$, and his pulse was 130 beats $/ \mathrm{min}$. The medic administered supplemental oxygen, but the oxygen saturation remained under $90 \%$. $\mathrm{He}$ decided to definitively control the patient's airway, but was uncomfortable in sedating and intubating the patient. Instead, the medic performed an open surgical cricothyrotomy without complication (Figure 1).

Upon further assessment, the medic found an open chest wound and treated it with a needle thoracostomy and an occlusive dressing. The patient remained tachycardic but normotensive. The medic resuscitated him with a hypertonic saline solution administered intravenously. The patient also received intravenous antibiotics.

The patient was evacuated by helicopter to a field hospital at Kandahar Airfield, where we continued treating his injuries. When the patient arrived at the hospital 4 hours after the injury occurred, his vital signs were stable and his airway was secure. In the operating theatre, we stabilized his facial wounds, converted his cricothyrotomy to a formal tracheotomy, inserted a chest tube and amputated his left arm and leg. The patient survived his injuries and was eventually discharged from hospital.

Caring for trauma victims on the battlefield is difficult. Medics often work under fire in blackout conditions and extreme temperatures, and on rugged terrain. The biggest challenge is that medics work independently despite a lack of trauma experience before deployment. Battlefield injuries are challenging to manage, even for experienced clinicians. For example, blast trauma may include multiple injuries, such as penetrating injuries from shrapnel, hyperbaric injury from over- pressure, blunt injury from the blast wave and burns. ${ }^{1}$

To meet these challenges, medics receive training that prepares them to treat common, preventable causes of death on the battlefield, including acute airway obstruction, tension pneumothorax and exsanguination from injury to the extremities, and it prioritizes these treatments based on the realities of combat situations. ${ }^{2}$ For example, while grave danger from hostile action persists, only tourniquet placement is used to control arterial extremity hemorrhage. After patients are removed to a safer location, acute airway and breathing issues are managed.

Among other things, tactical combat casualty care recommends early consideration of open surgical cricothyrotomy because inexperienced military medics are unlikely to intubate battlefield trauma patients successfully. ${ }^{2}$ Emergency cricothyrotomy is a dramatic, lifesaving procedure used to gain prompt access to an otherwise compromised and inaccessible airway. Before deploy-

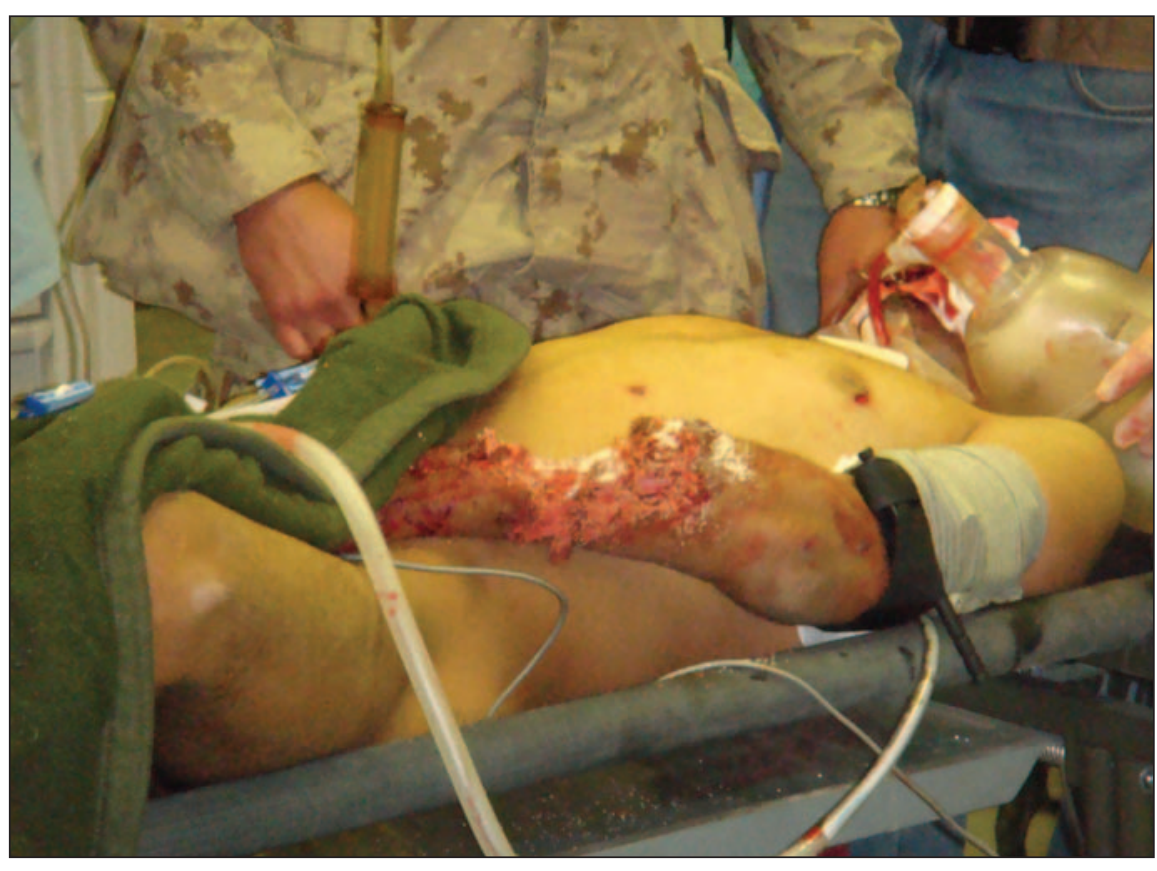

Figure 1: A 19-year-old Afghan man sustained extensive facial injuries and lost parts of his left forearm and left lower leg after a blast from an improvised explosive device, causing extensive soft tissue, neurovascular and bone injury. A medic performed an open surgical cricothyrotomy to secure the man's airway. 


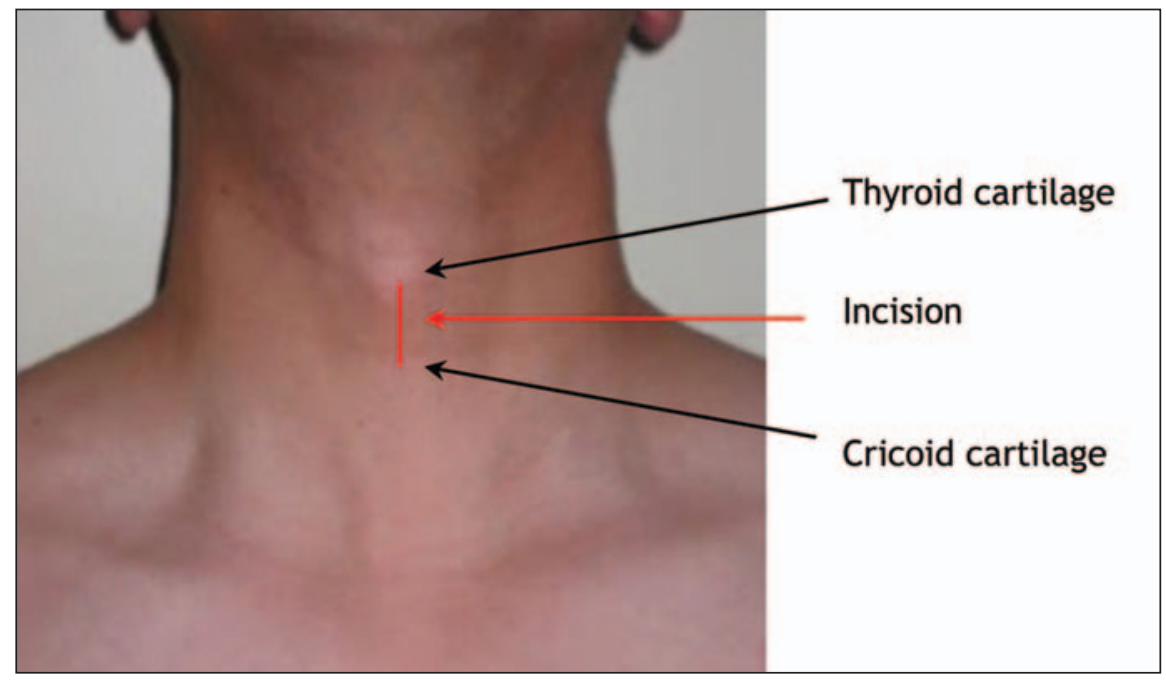

Figure 2: Surface landmarks for performing cricothyrotomy.

ing to Afghanistan, military medics participate in a Canadian Forces traumamanagement course, using simulators and animal models to practise cricothyrotomy and other skills.

DiGiacomo and colleagues described the technique of surgical cricothyrotomy in detail. ${ }^{3}$ To perform a cricothryotomy, an endotracheal or tracheotomy tube of appropriate size is prepared. A surgeon, if he or she is right-handed, then stands on the patient's right side and stabilizes the cricoid with the thumb and index finger of his or her left hand, applying a slight downward pressure to help draw the

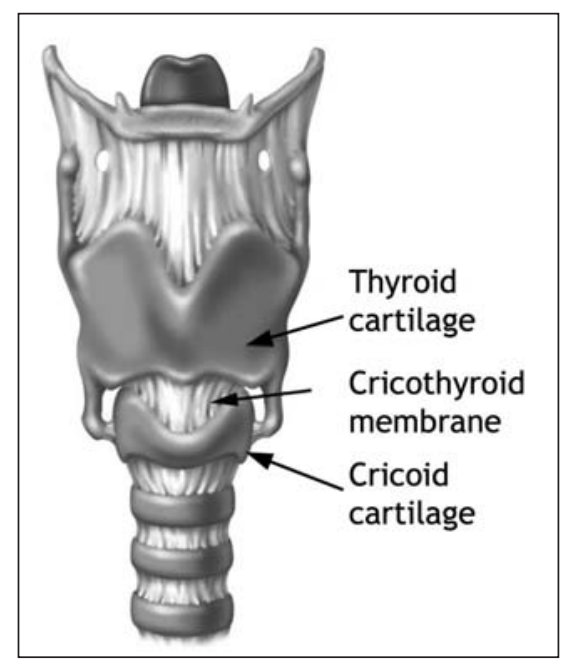

Figure 3: Surgical anatomy for cricothyrotomy. Reproduced with permission from Lippincott Williams \& Wilkins (Walls RM et al. ${ }^{6}$ ) $\subsetneq 2000$. skin edges apart after the cut is made. A number I5 scalpel is used to make a longitudinal midline incision, about $\mathrm{I} .5 \mathrm{~cm}$ in length, from the thyroid cartilage to the cricoid cartilage (Figure 2). A longitudinal incision is preferred to avoid bleeding complications from anterior neck veins. The incision should cut through the skin and subcutaneous tissues down to the thyroid and cricoid cartilages, exposing the cricothyroid membrane (Figure 3). The scalpel is then used to make a transverse stab incision through the membrane into the airway. The handle of the scalpel (or a hemostat) is then used to dilate the opening in the membrane. Laying the scalpel aside, the previously prepared tube is inserted into the trachea, the cuff is inflated, and the tube is secured to the patient's neck. A stitch can be used to secure the tube, but medics are taught to use a safety pin. Clinical examination and other adjunct tests, such as capnography if available, are performed to confirm tube placement in the trachea.

Many physicians and medics may hesitate to perform emergency cricothyrotomy because of inexperience or anxiety, thereby potentially increasing airway trauma from further intubation attempts and increasing the risk of poor outcomes caused by hypoxia. To reduce delays and minimize improvization, "difficult airway" guidelines have been developed to help physicians manage these stressful situations. ${ }^{4}$ Prompt action is recommended whenever ventila- tion and oxygenation are impaired.

Emergency cricothyrotomy is recommended when definitive control of the airway is required and other options have been exhausted (Box I). Although many advanced methods of securing airways are available to anesthesiologists, military medics have limited options because of inexperience. Canadian Forces medics are taught to consider early surgical cricothyrotomy after 2 failed attempts to secure the airway by other means, or after I failed attempt in the presence of uncorrectable hypoxia and impaired ventilation. Cricothyrotomy should be immediately considered in the presence of mechanical airway obstruction. For medics working on the battlefield, immediate cricothyrotomy is often required because mechanical airway obstruction commonly occurs from penetrating or blast injury to the face and neck.

\section{Conclusion}

Although there are differences between managing trauma on a battlefield and managing trauma in civilian settings, there are also similarities, particularly in remote, rural areas where trauma practitioners must deal with critical injuries related to farming, forestry and mining, often without access to specialists and with enormous distances to travel in harsh climates. There is a need to enhance trauma-management skills in rural areas, ${ }^{5}$ and a number of courses have been developed including courses offered

Box 1: Circumstances in which to consider cricothyrotomy

Cricothyrotomy is recommended if

- there is a need for a definitive airway, and 2 attempts* to secure the airway using other means have failed; or

- the patient has impaired ventilation and uncorrectable hypoxia, and 1 attempt to secure the airway using other means has failed; or

- the patient has mechanical airway obstruction (e.g., facial fractures, direct airway injury, blood, broken teeth, vomit).

*The threshold of 2 attempts should be increased if the clinician is familiar with other advanced methods to secure the patient's airway. 
by the American College of Surgeons, including advanced trauma life support and rural trauma team development.

The Canadian Forces Health Services developed its tactical combat casualty care course for its military medics to prepare them to treat battlefield injuries. This course provides realistic treatment algorithms for medics, taking into account their relative clinical inexperience. In addition, it uses simulators and animal models to teach procedural skills, concentrating on open surgical cricothyrotomy for managing difficult airway situations. This approach to airway management may also benefit trauma victims beyond the battlefield.
LCdr John C. Macdonald MD

Department of Critical Care Medicine

University of Ottawa

Ottawa, Ont.

Canadian Field Hospital

Canadian Forces Base Petawawa

Canadian Forces Health Services

Petawawa, Ont.

Maj Homer C.N. Tien MD MSc

Department of Surgery

Sunnybrook Health Sciences Centre

University of Toronto

Toronto, Ont.

Canadian Field Hospital

Canadian Forces Base Petawawa

Canadian Forces Health Services

Petawawa, Ont.

This article has been peer reviewed.
Competing interests: None declared.

\section{REFERENCES}

I. DePalma RG, Burris DG, Champion HR, et al. Blast injuries. N Engl J Med 2005;352:1335-42.

2. Butler FK Jr, Hagmann J, Butler EG. Tactical combat casualty care in special operations. Mil Med I996; I6r(Suppl):3-г6.

3. DiGiacomo C, Neshat KK, Angus LD, et al. Emergency cricothyrotomy. Mil Med 2003; I68:54I-4.

4. American Society of Anesthesiologists Task Force. Practice guidelines for the management of the difficult airway. An update report by the American Society of Anesthesiologists task force on management of the difficult airway. Anesthesiology 2003;98:1269-77.

5. Rowe BH, Therrien S, Johnson C. Regional variations of northern health. The epidemic of fatal trauma in northeastern Ontario. Can J Public Health $1995 ; 86: 249-54$.

6. Walls RM, Murphy MF, Luten RC, et al, editors. Manual of emergency airway management, 2nd edition. Philadelphia: Lippincott, Williams \& Wilkins; 2004. p.I62.

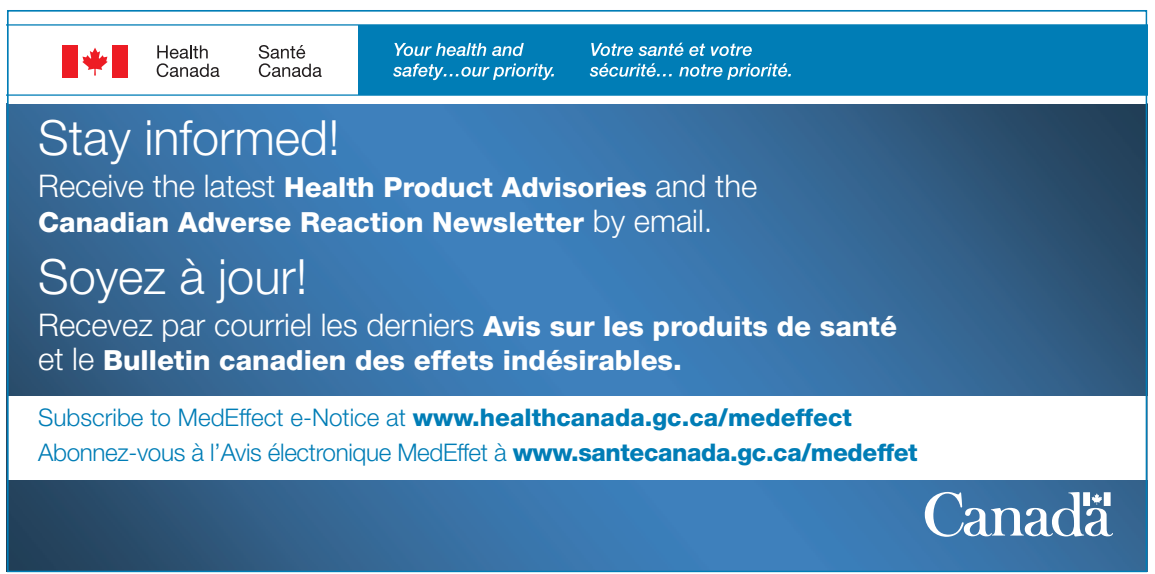

